\title{
Stage IVC Appendix Carcinoma AJCC v8
}

National Cancer Institute

\section{Source}

National Cancer Institute. Stage IVC Appendix Carcinoma A/CC v8. NCI Thesaurus. Code C134132.

Stage IVC includes: Any T, Any N, M1c, Any G. M1c: Metastasis to sites other than peritoneum. (AJCC 8th ed.) 